\title{
A relevância da ginástica laboral nas dores da coluna vertebral em decorrência a longa jornada de trabalho: revisão integrativa
}

Estudos mostram, que o estresse imposto pelas longas jornadas de trabalho, geralmente em más posturas e mobílias inadequadas, somados a movimento repetitivos e trabalhos com cargas em algumas profissões, resultam em alta prevalência de lombalgia e problemas posturais em trabalhadores. A Ginástica Laboral (GL), visa preparar o funcionário psicofisiologicamente antes de iniciar a sua jornada de trabalho e durante o expediente de trabalho, através de exercícios específicos, atuando assim, de forma terapêutica e preventiva, leve e de curta duração. Realizar um estudo de revisão integrativa, visando apresentar a relevância da ginástica laboral nas dores da coluna vertebral em decorrência a longa jornada de trabalho. Estudo realizado através de uma revisão de literatura integrativa onde foram analisadas as bases de dados da Literatura Latino-Americana e do Caribe em Ciências da Saúde (LILACS), Scientific Electronic Library Online (SciELO) e United States National Library of Medicine - PubMed. Foram selecionados os artigos que abordavam a ginástica laboral na saúde do trabalhador. Dos 43 artigos encontrados, somente 10 artigos atenderam aos critérios de inclusão previamente estabelecidos. O programa de ginástica laboral (PGL) é um potente instrumento preventivo e terapêutico, na jornada intensiva do trabalhador.

\section{The relevance of physical exercise in spinal pain due to long working hours: an integrative review}

\begin{abstract}
Studies show that the stress imposed by long working hours, usually in poor postures and inadequate furniture, combined with repetitive movements and work with loads in some professions, result in high prevalence of low back pain and postural problems in workers. The Gymnastics Labor (GL), aims to prepare the employee psychophysiologically before starting his work day and during working hours, through specific exercises, thus acting in a therapeutic and preventive, light and short term. To conduct an integrative review study, aiming to present the relevance of labor gymnastics in spinal pain due to long working hours. Study conducted through an integrative literature review, which analyzed the databases of Latin American and Caribbean Health Sciences Literature (LILACS), Scientific Electronic Library Online (SciELO) and United States National Library of Medicine - PubMed. Articles that addressed occupational gymnastics in workers' health were selected. Of the 43 articles found, only 10 articles met the previously established inclusion criteria. The occupational gymnastics program (PGL) is a powerful preventive and therapeutic instrument in the intensive worker's journey.
\end{abstract}

Keywords: Prevention; Physiotherapy; Labor gymnastics; Ergonomics; Absence from work; Back pain.

Topic: Fisioterapia

Reviewed anonymously in the process of blind peer
Received: $12 / 02 / 2019$

Approved: 29/05/2019
Tamires Costa Silva

Faculdade Einstein, Brasil

http://lattes.cnpq.br/5647103136576583

tamy.cs10@gmail.com

Fernando José de Vasconcelos Paes (iD)

Universidade Cidade de São Paulo, Brasil

http://lattes.cnpq.br/9295096774961141

http://orcid.org/0000-0001-5948-7229

ftfernandopaes@yahoo.com.br
Referencing this:

SILVA, T. C.; PAES, F. J. V.. A relevância da ginástica laboral nas dores da coluna vertebral em decorrência a longa jornada de trabalho: revisão integrativa. Medicus, v.1, n.2, p.9-16, 2019. DOI: http://doi.org/10.6008/CBPC2674-6484.2019.002.0002 


\section{INTRODUÇÃO}

No intuito de entender o quanto a ocupação do indivíduo pode ser determinante no aparecimento e desenvolvimento de certas doenças, há um interesse cada vez maior em estudar e analisar sobre o assunto. Portanto, sabe-se que as lesões musculoesqueléticas, como as dores na coluna tem sido uma das principais causadoras de aumento do absenteísmo, aumento da morbidade e concessão de auxílio doença (PINHO et al., 2001).

Segundo a Organização Mundial da Saúde, a relação da dor na coluna com o trabalho, pode ocorrer por fatores ergonômicos e traumáticos. Estimando-se que $70 \%$ a $85 \%$ da população, terá algum episódio de dor na coluna vertebral no decorrer da vida (MALTA et al., 2017). Cardoso (2019) afirma que o estresse imposto pelas longas jornadas de trabalho, geralmente em más posturas e mobílias inadequadas, somados a movimentos repetitivos e trabalhos com cargas em algumas profissões, resultam em alta prevalência de lombalgia e problemas posturais em trabalhadores, onde passam a adotar posturas ocupacionais inadequadas. Sendo assim, é importante ressaltar a construção de estratégias que foquem na prevenção e promoção da saúde do trabalhador, assegurando uma maior produtividade e qualidade no trabalho.

Uma revisão bibliográfica feita por Oliveira (2007), sobre a importância da GL na prevenção de doenças ocupacionais, ele cita um estudo realizado com 310.000 trabalhadores, onde o "problema na coluna" era uma das principais causas de afastamento nas grandes empresas, afirmando que os empresários investem pouco na prevenção do trabalhador. Então, ele mostra estudos realizados com empresas que aderiram ao programa ginástica laboral, reduzindo significamente o número de absenteísmo por conta de dores e lesões na coluna, relacionada ao trabalho.

Martins (2000) afirmam que a ginástica laboral pode ser classificada como preparatória e compensatória, visando preparar o funcionário psicofisiologicamente antes de iniciar a sua jornada de trabalho e durante o expediente de trabalho, através de exercícios específicos, realizados no ambiente de trabalho do indivíduo, atuando de forma terapêutica e preventiva, leve e de curta duração. Seus principais objetivos são: prevenir doenças causadas por traumas cumulativos, diminuir a fadiga muscular, prevenir e/ou corrigir vícios posturais, diminuir o número de acidentes de trabalho, aumentar a disposição do funcionário ao iniciar e retornar ao trabalho e promover maior integração no ambiente de trabalho.

Em relação aos exercícios específicos, Pulcinelli (1998) diz que a atividade física é eficaz pelo fato de o desempenho e o rendimento do trabalhador não ser constante, já que ao iniciar as suas atividades rotineiras no trabalho, o organismo começa rapidamente a adaptar-se aos processos fisiológicos, de acordo com as exigências do trabalho. $O$ tempo de adaptação inicial, onde o indivíduo atinge o seu limite de rendimento, dura aproximadamente duas horas.

Após este período de adaptação, irá ocorrer a fadiga e/ou cansaço, onde o desempenho do trabalhador começa a diminuir. Com a realização de pausas no início dessa fase de baixo rendimento, tornase visível a melhora desses sintomas de improdutividade, tornando o desempenho do trabalhador satisfatório. 
Martins (2000) citam em seu artigo que existem algumas etapas que deverão ser realizadas, para que a implantação da ginástica laboral tenha sucesso, sendo elas: 1o: avaliação e diagnóstico, observando a aptidão física, qualidade de vida, biomecânica e ergonomia, a fim de permitir uma correta adequação da atividade física; 2o: planejamento e estruturação do programa, prevendo inclusive a motivação, compreensão e aceitação do programa por parte dos funcionários; 3: conscientização de todos os funcionários da empresa sobre os problemas da má postura (dentro e fora do trabalho), sua prevenção e o incentivo à prática regular da atividade física; 4o: possibilitar ajustes antes da sua expansão a outros setores e 5o: avaliação dos resultados, incluindo as áreas da qualidade empresarial, produtividade e qualidade de vida. Dessa maneira, este artigo científico teve como objetivo apresentar a relevância da ginástica laboral nas dores da coluna vertebral em decorrência a longa jornada de trabalho.

\section{METODOLOGIA}

Trata-se de uma revisão integrativa da literatura, sobre os efeitos da ginástica laboral em indivíduos que sofrem de dores na coluna vertebral em decorrência a longa jornada de trabalho. As etapas seguintes foram: elaboração da pergunta norteadora, busca na literatura e análise crítica dos artigos. A pergunta norteadora que subsidiou a revisão foi: como a ginástica laboral pode contribuir com as dores na coluna, causada por longas horas de trabalho? Os artigos foram encontrados através das bases de dados da Literatura Latino-Americana e do Caribe em Ciências da Saúde (LILACS), Scientific Electronic Library Online (SciELO) e United States National Library of Medicine - PubMed. As palavras - chave utilizadas foram: prevenção. Fisioterapia. Ginástica laboral. Ergonomia. Afastamento do trabalho. Dor na coluna. A busca na literatura gerou 43 artigos, sendo publicados a partir de 2000 até 2019.

Como critérios de inclusão para a seleção dos artigos, os seguintes parâmetros foram analisados: artigos com textos completos disponíveis, ano de publicação (2000-2019), idioma português e/ou inglês, temas que abordassem a ginástica laboral no trabalho e a relação da saúde do trabalhador com as dores na coluna. Foram excluídos, os artigos que abordassem patologias distintas relacionadas a saúde do trabalhador, diferentes tratamentos relacionados a fisioterapia no trabalho preventivo, temas que abordassem a saúde do trabalhador de uma forma generalizada e os que não citassem a ginástica laboral.

Para facilitar a leitura e interpretação dos artigos, foi elaborada uma tabela com os seguintes tópicos: autor e ano do artigo publicado, título do artigo e síntese das conclusões. Em seguida, os principais conceitos foram classificados em torno de eixos centrais para a realização da discussão e, por fim, foi feita uma conclusão através dos pontos de convergência e divergência encontrados.

\section{RESULTADOS}

Dos quarenta e três (43) artigos encontrados, apenas vinte (10) preencheram os critérios de inclusão e vinte e três (33) não preencheram os critérios de inclusão, sendo treze (13) por abordarem patologias distintas relacionados a saúde do trabalhador; dez (10) por não abordarem a coluna vertebral durante a pesquisa; seis (06) por abordarem diferentes tratamentos relacionados a fisioterapia no trabalho preventivo 
e quatro (04) por abordarem a saúde do trabalhador de uma forma generalizada. Dos quarenta e três (43) artigos selecionados, vinte (20) foram encontrados na base de dados da Literatura Latino-Americana e do Caribe em Ciências da Saúde (LILACS), dez (10) foram encontrados no Scientific Electronic Library Online (SciELO) e treze (13) no United States National Library of Medicine - PubMed (Figura 1).

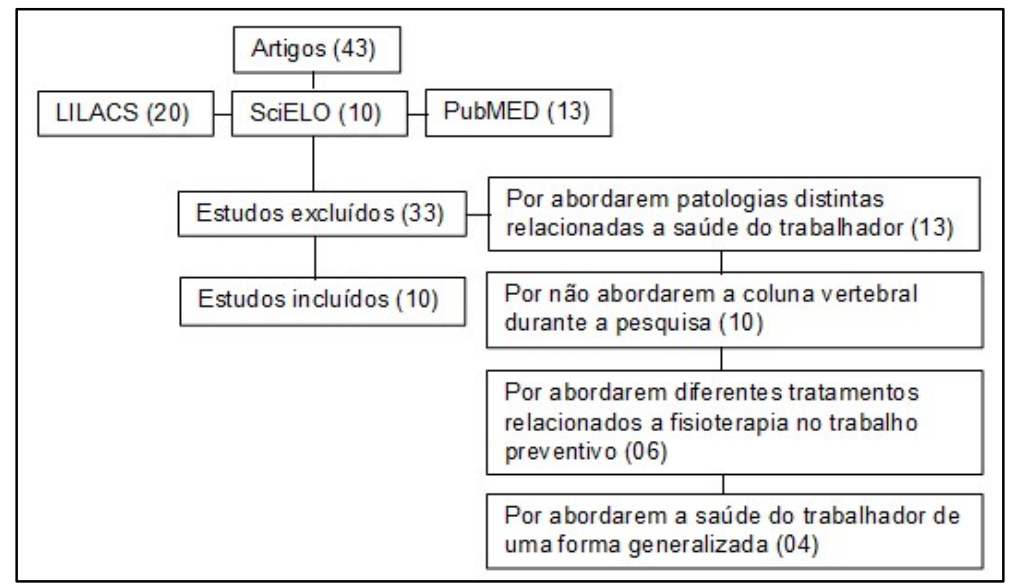

Figura 1: Fluxograma da seleção dos artigos.

Foram selecionados pela busca eletrônica nas bases de dados dez (10) amostras de evidências relevantes ao tema abordado (Tabela 1 ).

Tabela 1: Caracterização das publicações incluídas na revisão integrativa, segundo autor/ano, título e síntese das conclusões

\begin{tabular}{|c|c|c|}
\hline Autor/Ano & Título & Síntese das conclusões \\
\hline Oliveira, 2007. & $\begin{array}{l}\text { A importância da ginástica laboral na } \\
\text { prevenção de doenças ocupacionais. }\end{array}$ & $\begin{array}{l}\text { A ginástica laboral é eficiente na prevenção das doenças ocupacionais, } \\
\text { na melhoria da qualidade de vida do trabalhador e na diminuição do } \\
\text { absenteísmo. }\end{array}$ \\
\hline $\begin{array}{l}\text { Santos et al., } \\
2007 .\end{array}$ & $\begin{array}{l}\text { Benefícios da ginástica laboral na } \\
\text { prevenção dos distúrbios } \\
\text { osteomusculares relacionados ao } \\
\text { trabalho. }\end{array}$ & $\begin{array}{l}\text { Após uma intervenção através do programa de ginástica laboral, houve } \\
\text { uma redução considerável da dor das funcionárias e melhora da } \\
\text { qualidade de vida em relação às condições de trabalho, preparação } \\
\text { psicossocial, melhoria do relacionamento interpessoal, estado de } \\
\text { humor, motivação e disposição para enfrentar a jornada de trabalho, } \\
\text { atuando positivamente na prevenção e tratamento das doenças } \\
\text { ocupacionais. }\end{array}$ \\
\hline $\begin{array}{l}\text { Rodrigues, } \\
2009 .\end{array}$ & $\begin{array}{l}\text { Análise da eficácia de um programa } \\
\text { de cinesioterapia/ginástica laboral }\end{array}$ & $\begin{array}{l}\text { Analisou-se no trabalho apresentado que três meses de aplicação da } \\
\text { ginástica laboral é muito pouco para se verificar grandes melhoras em } \\
\text { relação a queixas de dores/desconfortos dos trabalhadores, porém } \\
\text { houve diminuição considerável das queixas dos participantes em região } \\
\text { lombar. }\end{array}$ \\
\hline $\begin{array}{l}\text { Candotti et al., } \\
2011 .\end{array}$ & $\begin{array}{l}\text { Efeitos da ginástica laboral na dor nas } \\
\text { costas e nos hábitos posturais } \\
\text { adotados no ambiente de trabalho. }\end{array}$ & $\begin{array}{l}\text { Os resultados demonstraram que a ginástica laboral foi eficaz na } \\
\text { diminuição da intensidade e frequência da dor, na correção dos hábitos } \\
\text { posturais durante o trabalho, melhorando a postura sentada. A GL é } \\
\text { capaz de produzir efeitos positivos sobre a dor nas costas de indivíduos } \\
\text { que trabalham por longos períodos na posição sentada. }\end{array}$ \\
\hline $\begin{array}{l}\text { Freitas-Swerts, } \\
2014 .\end{array}$ & $\begin{array}{l}\text { Efeitos da ginástica laboral } \\
\text { compensatória na redução do } \\
\text { estresse ocupacional e dor } \\
\text { osteomuscular }\end{array}$ & $\begin{array}{l}\text { Se tratando da coluna vertebral, houve diminuição dos sintomas de } \\
\text { dor, redução da sua intensidade e ausência de sintomas em todos os } \\
\text { seus segmentos no pós-teste, sugerindo que a GL conseguiu abolir } \\
\text { sintomas álgicos dos participantes e que a diminuição dos sintomas, } \\
\text { nos segmentos de pescoço, cervical, costas superiores, médias e } \\
\text { inferiores foram estatisticamente significativa. }\end{array}$ \\
\hline $\begin{array}{l}\text { Bezerra et al., } \\
2015 .\end{array}$ & $\begin{array}{l}\text { Os benefícios da ginástica laboral } \\
\text { para prevenção de dores } \\
\text { osteomusculares em professores da } \\
\text { escola Gesner Teixeira/ Gama-DF. }\end{array}$ & $\begin{array}{l}\text { Os resultados alcançados após a aplicação da ginástica laboral, } \\
\text { influenciaram na qualidade de vida e no trabalho dos participantes, } \\
\text { diminuindo as dores, nível de estresse e fadiga, conscientizado os } \\
\text { participantes a realizarem a GL. }\end{array}$ \\
\hline $\begin{array}{l}\text { Franciscatto et } \\
\text { al., } 2016 .\end{array}$ & $\begin{array}{l}\text { Efeitos de um programa de ginástica } \\
\text { laboral sobre sintomas de dor e fadiga } \\
\text { em trabalhadores. }\end{array}$ & $\begin{array}{l}\text { Mostrou-se resultados favoráveis de um programa de GL sobre a } \\
\text { redução de sintomas associados à dor cervical e a fadiga. Evidenciando } \\
\text { a importância da inserção desses programas no ambiente de trabalho, }\end{array}$ \\
\hline
\end{tabular}




\begin{tabular}{|c|c|c|}
\hline & & $\begin{array}{l}\text { contribuindo para a promoção da saúde do trabalhador e a prevenção } \\
\text { de lesões ocupacionais. }\end{array}$ \\
\hline $\begin{array}{l}\text { Ribeiro Neto, } \\
2018 .\end{array}$ & $\begin{array}{l}\text { Análise da eficácia de um protocolo } \\
\text { de ginástica laboral implantado em } \\
\text { uma instituição de ensino superior no } \\
\text { sul do Espírito Santo. }\end{array}$ & $\begin{array}{l}\text { Observou-se melhora de } 70 \% \text { do desconforto e dor, principalmente em } \\
\text { coluna, ombros e pescoço, em que o programa de ginástica laboral era } \\
\text { oferecido com frequência de três dias por semana. }\end{array}$ \\
\hline $\begin{array}{l}\text { Souza et al., } \\
2019 .\end{array}$ & $\begin{array}{l}\text { A influência da ginástica laboral nos } \\
\text { distúrbios } \quad \text { osteomusculares } \\
\text { relacionados ao trabalho. }\end{array}$ & $\begin{array}{l}\text { Sendo as regiões superior e inferior das costas mais afetada, do grupo } \\
\text { de trabalhadores aderidos ao programa de GL associando isto ao perfil } \\
\text { dos funcionários avaliados que trabalhavam por horas prolongadas na } \\
\text { posição sentada em um escritório, foi possível verificar que a GL pode } \\
\text { promover efeitos benéficos sobre os distúrbios osteomusculares. }\end{array}$ \\
\hline $\begin{array}{l}\text { Cardoso, } \\
2019 .\end{array}$ & $\begin{array}{l}\text { Ginástica laboral com relação à } \\
\text { prevenção das doenças relacionada } \\
\text { ao trabalho. }\end{array}$ & $\begin{array}{l}\text { A ginástica laboral contribuiu na melhoria da dor, melhoria na } \\
\text { disposição para o trabalho e ajuda a evitar lesões. }\end{array}$ \\
\hline
\end{tabular}

\section{DISCUSSÃO}

As lesões musculoesqueléticas tornaram-se um grande problema de saúde pública, onde as queixas e dores crônicas, relacionadas a coluna vertebral ganharam uma atenção maior. Entre elas estão: ciatalgias, cervicalgias, dores torácicas, transtornos dos discos intervertebrais, espondiloses, radiculopatias, e as dores lombares. Podendo ocasionar diferentes graus de incapacidade funcional, quando associadas à classe trabalhadora, por sua característica incapacitante (VIEIRA et al., 2013). Em setembro de 1990, a saúde do trabalhador foi definida pela lei federal 8.080, como um conjunto de atividades que se destinam à promoção e proteção da saúde dos trabalhadores, assim como visa à recuperação e reabilitação da saúde dos trabalhadores submetidos aos riscos e agravos advindos das condições de trabalho (OLIVEIRA, 2007). Sendo assim, um dos recursos utilizados na saúde do trabalhador é o programa de ginástica laboral (PGL), que é realizada coletivamente, durante a jornada de trabalho, onde a atividade física proposta, de leve e curta duração, é de acordo com a função exercida pelo trabalhador, com o objetivo de diminuir doenças por traumas cumulativos, prevenir a fadiga muscular, prevenir e/ou reduzir sintomas dolorosos na região da coluna vertebral e corrigir vícios posturais (BEZERRA et al., 2015).

No presente estudo, foi possível observar que as pesquisas selecionadas utilizaram principalmente questionários sobre estresse, jornada de trabalho, pausa para descanso, tipo de tarefa e dor, para avaliar o trabalhador. Foi observado também, relatos de queixa de dores na coluna, pelos trabalhadores, onde apontam a possível relação com o trabalho realizado na mesma posição e de forma contínua. Outro marco importante, foi a realização da GL e seus efeitos positivos no dia a dia do trabalhador.

No estudo de Santos et al. (2007), realizou-se uma amostra com (40) funcionárias dos serviços gerais, avaliadas pré e pós o programa de GL por meio de questionários. A GL foi realizada duas vezes na semana, durante as pausas da jornada de trabalho, com duração de trinta 30 minutos, num período de seis meses, no total de 48 sessões. Em relação a jornada de trabalho, todas estavam dentro do limite permitido. Antes da realização da $\mathrm{GL}$, relataram dores na cervical $(50 \%)$ e pós $\mathrm{GL}(47 \%)$, na coluna dorsal, pré $44 \%$ e pós $25 \%$ e coluna lombar, pré $69 \%$ e pós $54 \%$. Comprovando assim, a redução e melhora significativa da dor na coluna, após a realização do programa ginástica laboral.

No intuito de analisar os benefícios da implantação da GL em funcionários de diversos setores, Rodrigues (2009), realizou uma amostra com 20 funcionários, avaliando pré e pós a GL por meio de 
questionários, três vezes na semana, durante 15 minutos no início da jornada. Em relação as dores no início e no final do expediente: $24 \%$ sentiam na região cervical e $44 \%$ na região lombar e ao fim do expediente $28,57 \%$ sentiam dor na região cervical e $33,33 \%$ na região lombar. Onde, $70 \%$ achavam importante a realização e conscientização da ginástica laboral no início do expediente e $95 \%$ achavam muito importante a realização no final do expediente. Após a implantação da GL, somente houve melhora significativa, naqueles que se queixavam-se de dores na região lombar (33\%). Concluindo assim, a importância de planejamento e orientação para cada função a ser trabalhada, onde a GL ajuda na diminuição considerável de queixas de dores lombares.

Candotti et al. (2011), ao realizar um estudo com 30 trabalhadores do setor administrativo, divididos em grupo controle ( $n=15)$ e grupo experimental $(n=15)$ e submetidos a sessões de $G L$ durante três meses, onde ambos os grupos foram avaliados por um questionário de dor e postura observou que a GL proporcionou diminuição da intensidade e da frequência da dor aos trabalhadores do grupo experimental, e mudança do hábito postural durante o trabalho, melhorando a postura sentada, assim a GL constitui como uma ação educativa que busca a conscientização e promoção da saúde. A lombalgia referida pelos indivíduos pode estar associada a permanência por longos períodos em posturas incorretas, gerando desequilíbrios musculares, os quais remetem novamente a má postura, e um círculo vicioso.

Segundo Freitas-Swerts (2014), em seu estudo realizado com 30 funcionários de setores administrativos, observou-se que a coluna vertebral obteve uma redução de sintomas de dor e de intensidade. Em seu estudo, destaca-se a redução da dor (de 26,7\% para 6,7\%), cervical (de 16,7\% para 0\%), costas superiores (de $40 \%$ para 3,3\%), médias (de 26,7\% para 3,3\%) e inferiores (de 33,3\% para 10\%). Além da redução da intensidade dolorosa, constatou-se ausência de queixas em todos esses segmentos de coluna vertebral no pós-teste, sugerindo que a GL conseguiu abolir sintomas álgicos em alguns trabalhadores.

Bezerra et al. (2015), realizou um estudo com 20 professores, onde 70\% relataram dor na coluna. Após a realização do programa de ginástica laboral, os resultados demonstraram a diminuição das dores, nível de estresse e fadiga, conscientizando os participantes a praticar exercício durante o expediente de trabalho. Já no estudo realizado por Franciscatto et al. (2016), participaram 23 servidores públicos, divididos aleatoriamente em dois grupos, onde o primeiro grupo participou de palestras e os outros participaram da ginástica laboral, durante 08 semanas, três vezes por semana e duração de 50 minutos cada encontro. 0 presente estudo apresentou resultados significativos quanto à redução dos sintomas de fadiga e de dores cervicais nos servidores que participaram do protocolo de ginástica laboral. Já o grupo que participou de palestras, não obteve alterações dos sintomas antes e após o acompanhamento do estudo. Ribeiro Neto (2018) verificaram a eficácia da GL com 106 colaboradores de uma empresa, quando aplicou um questionário pré e pós a GL onde a atividade tinha duração de 10 a 15 minutos, duas vezes por semana em dias alternados, durante cinco meses. Com isso, 36 funcionários se queixaram de dor na coluna e 34 na região do pescoço. Observando-se uma melhora de $70 \%$ no quesito desconforto e dor.

Em um estudo recente, Cardoso (2019) iniciaram um estudo com 40 funcionários, 2 vezes por semana, durante 1 mês e com duração de 15 minutos cada encontro, onde se mostrou o quanto a GL pode 
ser eficaz nas dores, 50\% relataram dor intensa na coluna após a jornada de trabalho e após a realização do programa houveram melhoras significativas das mesmas. Por fim, Souza et al. (2019), ao realizar um estudo com 31 funcionários, foram submetidos a 16 sessões de GL, realizadas 2 vezes por semana, com duração média de 15 minutos. Houve uma diminuição das queixas de dor/formigamento principalmente na parte superior das costas.

As sessões de GL mostraram-se eficazes sobre os distúrbios osteomusculares dos funcionários do GE, diminuindo os relatos de queixas de dor/formigamento para a realização das atividades laborativas, domésticas e de lazer, bem como diminuição das consultas com profissionais de saúde. Nesta revisão, não foram encontradas publicações que apresentassem resultados negativos ou contraditórios de trabalhos, que fizeram o uso da ginástica laboral nas dores da coluna vertebral. Como limitações deste estudo destacam-se o número limitado de estudos analisados devido ao enfoque restrito da pesquisa. Mesmo com estas limitações, os resultados demonstraram a importância da prevenção para melhor qualidade de vida dos trabalhadores.

O que todos têm em comum, além das melhoras significativas das dores na região da coluna, é a melhora também no ambiente de trabalho, proporcionando momento de relaxamento, melhora da autoestima dos funcionários, na união com os colegas de trabalho, melhora da disposição para a realização da função e ajudando a evitar outros tipos de lesões ocupacionais.

\section{CONCLUSÕES}

Ao apresentar a relevância da ginástica laboral nas dores da coluna vertebral em decorrência a longa jornada de trabalho, foi possível notar o alto índice de dor crônica na coluna, capaz de limitar o trabalhador a realizar as suas atividades de vida diária (AVD'S), em executar suas funções no trabalho, reduzindo a produtividade do indivíduo, aumentando o absenteísmo no trabalho e consequentemente, afetando negativamente a empresa. O programa ginástica laboral, tem como possibilidade diminuir as dores relatadas diariamente e prevenir lesões por esforço repetitivo e doenças osteomusculares relacionadas ao trabalho. Com o passar dos anos, observa-se que as empresas estão dando cada vez mais, a atenção necessária aos funcionários, no sentido de prevenir e promover saúde, durante a jornada de trabalho. Faz-se necessário, a implantação de programas educativos, relacionados a ergonomia e atividade física, onde os funcionários e empresários possam entender o objetivo e o impacto positivo da ginástica laboral, na jornada intensiva do trabalhador. Havendo a continuidade do programa de ginástica laboral, pois é um potente instrumento preventivo e terapêutico.

\section{REFERÊNCIAS}

BEZERRA, G. M. R.; FELIX, K. D.. Os benefícios da ginástica laboral para prevenção de dores osteomusculares em professores da escola Gesner Teixeira/Gama-DF. Revista de Saúde da Faciplac, v.2, n.1, 2015

CANDOTTI, C. T.; STROSCHEIN, R.; NOLL, M.. Efeitos da ginástica laboral na dor nas costas e nos hábitos posturais adotados no ambiente de trabalho. Revista Brasileira de Ciências do Esporte, v.33, n.3, 2011.

CARDOSO, A. K. M.. Ginástica laboral com relação à prevenção das doenças relacionada ao trabalho. Revista Psicologia \& Saberes, v.8, n.11, p.245-254, 2019. 
FRANCISCATTO, C.; ROCHA, J. C.; LARA, S.. Efeitos de um programa de ginástica laboral sobre sintomas de dor e fadiga em trabalhadores. Saúde, Santa Maria, v.42, n.2, p.107-114, 2016.

FREITAS-SWERTS, F. C. T.; ROBAZZI, M. L. C. C.. Efeitos da ginástica laboral compensatória na redução do estresse ocupacional e dor osteomuscular. Revista Latino-Americana de Enfermagem, v.22, n.4, p.629-636, 2014.

MALTA, D. C.; LIVEIRA, M. M.; ANDRADE, S. S. C. A.; CAIAFFA, W. T.; SOUZA, M. F. M.; BERNAL, R. T. I.. Fatores associados à dor crônica na coluna em adultos no Brasil. Revista de Saúde Pública, v.51, p.1s-12s, 2017. DOI: https://10.1590/S1518$\underline{8787.2017051000052}$

\section{MARTINS, C. O.. Efeitos da ginástica laboral em servidores} da Reitoria da UFSC. Dissertação (Mestrado em Engenharia de Produção) - Universidade Federal de Santa Catarina, Florianópolis, 2000.

OLIVEIRA, J. R. G.. A importância da ginástica laboral na prevenção de doenças ocupacionais. Revista de Educação Física, v.76, n.139, 2007.

PINHO, L.; ARAÚJO, M. G. F.; GOES, S. R.; SAMPAIO, R. F. Dores na coluna em profissionais de enfermagem. Acta Fisiátrica, v.8, n.2, p.75-81, 2001.
PULCINELLI, A. J.. Curso de capacitação para coordenadores do programa ginástica na empresa. Brasília: SESI, 1998.

RIBEIRO NETO, N. C.. Análise da eficácia de um protocolo de ginástica laboral implantado em uma instituição de ensino superior no sul do Espírito Santo. Conhecendo, v.3, n.1, 2018.

RODRIGUES, F. S.. Análise da eficácia de um programa de cinesioterapia/ginástica laboral. Rev. Ergo Physical, v.3, n.5, p.53-64, 2009.

SANTOS, A. F.; ODA, J. Y.; NUNES, A. P. M.; GONÇALVES, L.; GARNÉS, F. L. S.. Benefícios da ginástica laboral na prevenção dos distúrbios osteomusculares relacionados ao trabalho. Arquivos de Ciências da Saúde da UNIPAR, v.11, n.2, 2007.

SOUZA, J. O.; MARTINS, M. T.; SOUZA, C. M.; BAPTISTA, I. C.; CARDOSO, L. P.; MEDEIROS, G. B.; CRUZ, A. T.; JANUÁRIO, P. $O$.. A influência da ginástica laboral nos distúrbios osteomusculares relacionados ao trabalho. Revista de Atenção à Saúde, v.16, n.58, 2019. DOI: http://doi.org/10.13037/ras.vol16n58.5487

VIEIRA, M. V. P.; ALCÂNTARA, D. S.. Prevalência de dor lombar crônica em trabalhadores de enfermagem: revisão bibliográfica. Science \& Health, Manaus, v.1, n.3, p.49-55, 2013.

A CBPC - Companhia Brasileira de Produção Científica (CNPJ: 11.221.422/0001-03) detém os direitos materiais desta publicação. Os direitos referem-se à publicação do trabalho em qualquer parte do mundo, incluindo os direitos às renovações, expansões e disseminações da contribuição, bem como outros direitos subsidiários. Todos os trabalhos publicados eletronicamente poderão posteriormente ser publicados em coletâneas impressas sob coordenação da Cognitionis Publishing, da Companhia Brasileira de Produção Científica e seus parceiros autorizados. Os (as) autores (as) preservam os direitos autorais, mas não têm permissão para a publicação da contribuição em outro meio, impresso ou digital, em português ou em tradução. 